\title{
The typology on subjectivity of re-socialization barriers among retired footballers
}

\author{
Wangsung Myung, Kwangho Park*, \& Kyunghwan Jung \\ Yonsei University
}

\begin{abstract}
[Purpose] The purpose of this study is to classify the subjectivity of re-socialization barriers among retired footballers. [Methods] Q methodology was conducted to identify constraint factors contributing to social adjustment and reemployment perceived by 28 P-samples. [Results] Re-socialization barriers were classified as 'Type I: Internal-constraint', 'Type II: External-constraint', 'Type III: Internal-conflict', and 'Type IV: External-conflict'. These types provided a variety of academic and practical discussions, depending on where the barriers are taken from (internal and external) and what depends on them (objective conditions and subjective ideas). [Conclusions] This study focused on the subjective structure of retired footballers and complemented traditional methodology focusing on hypothesis testing. Therefore, each type found in this study provides useful information not only in follow-up study on retired athletes, but also in policy-making decision such as support projects.
\end{abstract}

Key words: Footballer, Retirement, De-socialization, Re-socialization, Barrier, Q methodology, Subjectivity

\section{서 론}

현대인에게 은퇴란 일정 수준의 연령에서 직면하는 불 가피한 사건이다. 실제로 국내 경제활동 참가율은 15 세 부터 49세까지 지속적인 증가 추이를 보이다가 50세 이 후부터 급격하게 감소하고 있다(Korean Statistical Information Service, 2019). 이러한 사실은 우리나라 국민들이 평균 50 60대에 공식적인 은퇴를 경험하고 있 음을 보여준다.

일반 노동시장과 달리 스포츠선수가 경험하는 은퇴의 양상은 그 시기와 원인에 상당한 차이가 있으며, 보다 비 관적인 경향을 보이고 있다. 국내 은퇴 스포츠선수의 실 업률은 $33.8 \%$ 이며, 취업자 중 비정규직 종사자는

논문 투고일 : 2019. 11. 11.

논문 수정일 : 2019. 12. 02.

게재 확정일 : 2019. 12. 11.

* 교신저자 : 박광호(pkh0977@gmail.com).
$64.6 \%$, 월 소득 200 만 원 미만은 $50.9 \%$ 로 나타났다 (Korean Sport \& Olympic Committee, 2018). 이러한 사실은 스포츠선수의 은퇴시기(평균 23세)를 고려했을 때(KSOC, 2018), 은퇴 후 사회·경제적 고립이 일반 노 동시장보다 더욱 심각함을 보여준다.

이에 Myung, Won \& Koo(2015)는 스포츠선수의 은 퇴를 네 가지 특징으로 분류 및 설명하였다. 첫째, 한정된 직업 수명이다. 스포츠선수의 은퇴는 주로 20 30대 연 령에서 발생하고 있으며, 이는 앞서 살펴본 일반 노동시 장에서의 은퇴 시기(50 60대)보다 상당히 이른 시기이 다. 둘째, 비자발적 은퇴이다. 스포츠선수는 스포츠 상 해, 일방적 계약 해지, 재계약 실패 등 은퇴 과정이 타의 적이면서 예측 불가능한 경우가 많다. 셋째, 소양 부족 및 사회부적응 문제이다. 이러한 특징은 어린 시절부터 학습 권으로부터 소외된 국내 학원 스포츠 체계에서 더욱 두드 러진다. 마지막으로 선수시절 얻은 부와 명성이다. 국가 대표 발탁 경험이 있거나 프로선수로서 성공적 커리어를 
쌓은 선수는 짧은 기간에 상당한 금전적 수입과 명성을 얻게 되지만 은퇴 후 삶이 빈곤한 사례가 적지 않다. 이처 럼 스포츠선수의 은퇴는 일반 노동시장과는 다른 양상을 보이고 있으며, 사회문화적 맥락으로부터 그 특수성을 이 해하는 작업이 필요하다.

이러한 문제의식을 기반으로 그동안 체육학계에서는 스포츠선수의 은퇴와 관련된 연구를 수차례 보고하였다. 종목별로 살펴보면, 농구(Chung, 2010), 배드민턴 (Jang \& Kim, 2016), 아이스하키(Park, \& Won, 2014), 에어로빅(Yoon, Kang, Yang, Yoo, Kim \& Kang, 2013), 육상(Lee \& Park, 2012), 태권도(Jeon \& Park, 2009), 테니스(Lim, 2015), 체조(Lee \& Park, 2009), 축구(Choi, Lim \& Jeon, 2018; Kim \& Hong, 2015; Myung et al., 2015), 핸드볼(Choi \& Chung, 2012), 복합 종목(Choi, 2014; Chung, 2007; Jang, 2016; Jeon, Won \& Lee, 2004; Kim, 2014; Kim \& Lee, 2016; Koo \& Park, 2002; Lee, 2008; $\mathrm{Seo}, 2012$ ) 등이다. 이들 연구는 양적 및 질적 접근을 통 해 스포츠선수의 은퇴 요인과 은퇴 후 삶에 관한 경험적 지식을 축적하는데 상당한 기여를 하였다. 더 나아가 이 들의 지적 노력은 최근 10 년 간 국내 스포츠선수의 은퇴 준비 및 재취업 지원과 같은 복지의 필요성 인식과 정책 실현으로 이어지기도 했다.

그러나 이러한 성과에도 불구하고 전통 방법론의 접근 은 은퇴 스포츠선수의 재사회화 장벽을 개인 내부의 관점 으로부터 유형화하는데 한계가 있었다. 주로 이론적 배경 (가설)에 근거하여 은퇴와 관련된 변수들 간의 관계(모 형)를 검증하였으며, 일부는 특정 종목 선수의 은퇴 경험 과 은퇴 후 삶을 서사적으로 기술하는데 그쳤기 때문이 다. 이는 스포츠선수의 은퇴에 영향을 미치는 변인과 특 정 종목의 사회문화적 특수성을 제시한 반면, 선수 개인 적 특성과 재사회화 장벽의 상호 관계를 이해하는데 한계 를 보이고 있다.

즉 재사회화라는 특정 현상에 관한 반응(신념, 관점, 견해, 이미지, 태도 등)을 개인 내면의 주관성 차이로부 터 추론하기 보다는 사전에 설계된 측정 문항과 표본 집 단의 응답으로 일반화한 것이다. 특히, 양적 접근(Jang, 2016; Kim, 2014; Kim \& Hong, 2015; Lee, 2008; $\mathrm{Seo}, 2012)$ 의 경우, 연구자 중심의 관점에서 은퇴 선수
는 객관적 측정의 대상으로 자신의 주관성을 능동적으로 표출하는데 한계가 있었다. 이는 그동안 사회현상의 본질 을 이해하는데 있어 주관성이 배제되어온 정상과학의 경 향이기도 하다(Kim, 2008).

또한, 국내 스포츠 분야에서 축구 종목이 차지하는 양 적 비율과 그 영향력에 비해 축구선수의 은퇴 과정과 재 사회화 과정에 관한 연구는 상대적으로 관심을 받지 못했 다. 특히, 국가대표팀 또는 프로구단과 같은 높은 수준의 경력을 지닌 은퇴 축구선수를 탐구 대상으로 한 연구는 상당히 제한적이다. Choi et al.(2018)은 은퇴 후 직장축 구팀으로 재입단한 자들로 그 대상과 연구 범위를 제한하 였으며, Kim \& Hong(2015)과 Myung et al.(2015)은 은퇴 선수가 아닌 현직 선수들을 대상으로 은퇴 인식 및 준비행동에 주목하였다. 이처럼 은퇴 프로축구선수를 대 상으로 재사회화 과정을 분석한 연구는 전무한 실정이다.

그 배경에는 다양한 원인이 있겠지만, 본 연구는 선행 연구를 통해 의미 있는 사실을 확인할 수 있었다. 그동안 스포츠선수 은퇴 연구는 비인기 또는 비대중적 종목에 주 목하는 경향이 지배적이었다. 앞서 열거한 선행연구들 역 시 일부 종목을 제외하고 프로스포츠리그가 존재하지 않 거나 학원스포츠에서 수급이 낮은 것이 그 특징이다. 에 어로빅 선수를 대상으로 한 Yoon et al.(2013)은 연구 필요성과 결과에서 해당 종목의 비대중성, 협소한 관련 직업, 저변 부실 등을 직접 언급하였다. Lee \& $\operatorname{Park}$ (2009)은 기계체조 선수들이 은퇴 후 체조 관련 직 종이 제한되어 있어 혼란을 겪는다고 하였으며, Lee \& $\operatorname{Park}(2012)$ 은 육상 선수들이 비인기 종목 출신이라는 이유로 은퇴 후 사회 진출에 어려움이 있다고 보고하였 다. 이처럼 선행연구들의 문제의식과 접근방식이 비인기 종목의 특수성으로부터 영향을 받아왔으며, 이러한 경향 은 연구 결과에서도 어렵지 않게 발견할 수 있다.

이와 달리 본 연구에서 주목한 축구는 국내뿐만 아니 라 세계적으로 강한 대중성과 풍부한 저변을 확보한 종목 으로서 은퇴 후 직업 전환이 보다 낙관적으로 전망된다. 그러나 현직 프로축구선수들의 은퇴 기대수준은 여느 스 포츠선수와 같이 불안정한 것으로 보고되어 왔다( Kim \& Hong, 2015; Myung et al., 2015). 더 나아가 국가 대표팀 및 프로구단과 같은 높은 수준의 경력을 갖춘 은 퇴 선수들이 그렇지 않은 선수와는 다른 차원의 고충(운 
동선수에 대한 고정관념, 사회적 인식, 타인의 관심과 시 선 등)을 겪고 있다는 연구도 적지 않게 보고된 바 있다 (Choi, 2014; Jeon et al., 2004; Lim, 2015). 이러한 점을 고려했을 때, 은퇴 프로축구선수의 재사회화 과정에 대한 이해는 비인기 종목이 주를 이루는 기존 연구에 다 양한 관점과 비교 논의를 제공할 수 있을 것이다. 무엇보 다 은퇴 프로축구선수의 재사회화 장벽, 즉 직업 전환 및 사회 적응 과정에서 경험(지각)한 사회·심리적 장벽은 은 퇴 선수 지원사업과 관련된 실용적 논의에도 기여할 수 있다.

이에 본 연구는 $\mathrm{Q}$ 방법론을 분석 틀로 차용하여 은퇴 프로축구선수들의 재사회화 장벽에 관한 수용인식(주관 성)을 유형화하는데 그 목적을 두고 있다. 연구 목적을 달 성하기 위해 다음과 같은 연구 문제를 설정하였다. 첫째, 은퇴 프로축구선수들이 수용한 재사회화 장벽의 유형은 무엇인가(유형분석). 둘째, 각 유형별 특징은 무엇인가 (유형해석). 셋째, 유형 간 분류기준(공통점 및 차이점) 은 무엇인가(논의).

\section{연구방법}

본 연구는 은퇴 프로축구선수들이 수용한 재사회화 장 벽에 주목하는 동시에 참여자의 내면적 관점에 보다 초점 을 두고자 한다. 피 관찰자를 개별적인 신념, 태도, 행동 을 지닌 주관성의 주체로 인식함으로써 재사회화 과정에 대한 본질적인 이해를 추구하기 위함이다. 구체적으로 $\mathrm{Q}$ 방법론이 그 대안적 접근이 될 수 있으며, 이를 본 연구의 분석 틀로 차용하여 전통 방법론의 한계를 극복하고자 한 다. $\mathrm{Q}$ 방법론은 재사회화 장벽에 관한 개인(여기서는 은 퇴 축구선수)의 주관성을 구조화하는데 유용한 접근 방 식으로 가설 검증보다는 가설 발견(추론)에 근접하기 때 문이다(Kim, 2008). 즉, Q방법론은 피 관찰자의 관점에 서 새로운 의미의 가설을 발견하는데 초점화된 방법으로 경험적 연구가 부족한 본 연구 대상에 유용한 분석 틀을 제공한다.

Q방법론은 Stephenson(1953)에 의해 처음 개발된 이후 국내에서는 $\operatorname{Kim}(1992,2008)$ 과 Korean Society for the Science Study of Subjectivity(2002,
2014)가 선도하고 있다. 국내 체육학에서는 학교체육 (Kim, 2019; Park, 2018), 생활체육(Choi, Chung, Jun \& Kim, 2011), 특수체육(Jung, Kim \& Lee, 2019; Kim, Kim, Park \& Lee, 2015), 노인체육 (Im, 2019; Kim, 2012), 스포츠마케팅 (Kim \& Son, 2017; Lee, Jeon \& Kim, 2011) 등 주로 스 포츠 참여자, 지도자 그리고 소비자 관련 연구에서 관 심을 받고 있다.

$\mathrm{Q}$ 방법론은 특정 현상(또는 체험)에 대한 개인의 주 관성 구조를 유형화하는 내재적 접근 방식을 취한다는 특징이 있다. 특히, 참여자의 지각적 판단에 의존하여 $\mathrm{Q}$-표본을 스스로 조작하고, 이를 통해 자아구조를 계량 적으로 유형(요인)화하기 때문에 양적 및 질적 속성을 모두 지니고 있다(McKeown \& Thomas, 2013). 이 처럼 $\mathrm{Q}$ 방법론은 그동안 전통방법론에서 과소평가되어 왔던 피 관찰자의 주관성에 의미를 부여하고, 가설 생 성 및 후속 연구를 위한 탐색적 기능에 유용하다(Kim, 2008). 이에 본 연구는 가설 추론적인 Q방법론을 분석 틀로 차용하여 은퇴 선수들이 지각(또는 경험)한 사회적 응 및 재취업 과정에서의 제약 요인(장벽)을 규명하였다.

\section{Q-표본(Q-sample 또는 Q-statement)}

본 연구는 Q-표본을 선정하기 위해 문헌고찰 및 심층 면담을 실시하였다. 먼저, 스포츠선수 은퇴 관련 선행연 구로부터 재사회화 및 진로장벽과 관련된 요인을 수집 및 분류하였다. 주로 은퇴 선수를 대상으로 척도 개발 및 변 인 간 관계를 검증한 양적 연구와 귀납적 접근을 차용한 질적 연구를 선별하였다.

다음으로 은퇴 프로축구선수를 대상으로 심층면담을 실시하였으며, 참여자 선정 기준은 다음과 같다. 첫째, $\mathrm{K}$ 리그 경력이 최소 3 년 이상인 자로 제한하였다. 이는 중 도탈락 학생선수, 실업팀 및 직장축구팀 선수 등 아마추 어 선수와 구분하기 위함이다. 둘째, 은퇴 후 5년이 경과 하지 않은 자로 취업 상태에 제한을 두지 않았다. 은퇴 후 재사회화에 대한 다양한 경험과 선명한 기억을 확보하기 위해서다. 마지막으로 자발적 참여 동의를 사전에 검토하 였다. 심층면담의 특성상 참여자의 적극적인 자세와 풍부 한 경험을 통해 자료의 포화상태를 기대할 수 있기 때문 
이다. 따라서 참여자 선정은 자료의 포화상태를 인지했을 때 중단하였다. 이러한 일련의 과정을 거쳐 총 5 명이 심 층면담에 참여하였다. 심층면담은 각 1 회씩 약 40 분에서 90분을 소요하였으며, 면담장소는 카페, 식당, 근무지 등 참여자가 선호하는 장소를 선택하였다. 면담 내용은 선수 경력, 은퇴원인, 은퇴 후 고충, 은퇴 후 재취업 과정 등 사 전에 공통 질문을 준비하여 반구조화된 면담을 진행하였다.

이를 통해 의견 집합체(concourse)인 총 57개(문헌 $=45$, 면담 $=12)$ 의 $\mathrm{Q}$-모집단 (Q-population)을 1 차로 구성하였다. 이후 전문가 집단(스포츠사회학 박사 2 명, 프로축구선수 2 명 $)$ 의 동료 검증을 통해 $\mathrm{Q}$-표본 간 중복 또는 유사하다고 판단되는 진술문은 표본 간 통합 처리하 였다. 추가로 본 연구 목적과 대상에 적합하지 않거나 내 용 타당도 오류가 의심되는 Q-표본을 제외하였다. 예컨 대, 은퇴 스포츠선수의 재사회화 장벽 요인으로 분류된 '유리천장', '성차별', ‘비인기 종목', ‘비대중적 종목' 등은 본 연구 대상인 남성 프로축구선수에 적합하지 않다고 판 단하여 $\mathrm{Q}$-표본 선정 과정에서 제외하였다. 이러한 일련 의 절차를 거쳐 총 16 개의 $\mathrm{Q}$ 표본을 최종적으로 선정하 였다. Q-모집단과 Q-표본에 관한 자세한 내용은 〈Table 1 , 〈Table 2〉와 같다.

\section{$\mathrm{P}$-표본(P-sample 또는 $\mathrm{Q}$-sorter)}

$\mathrm{P}$-표본은 앞서 추출한 $\mathrm{Q}$-표본을 분류하는 사람으로서 Q-sorter로 표현하기도 한다. Q방법론은 특정 변인 간 관계를 검증하는 양적 연구와 달리, 개인 간 심리적 주관 성을 유형화하는데 그 목적이 있다. 따라서 $\mathrm{P}$-표본의 크 기는 제한을 받지 않으며, 오히려 표본 크기가 클수록 개 인의 주관성을 파악하는데 방해가 되기도 한다(Watts \& Stenner, 2005). 그러나 Q-분석 과정에서 주성분 요인 분석의 용이성을 고려하여 $\mathrm{Q}$-표본보다 많은 $\mathrm{P}$-표본을 선 정하는 것이 일반적인 추세이다. 이에 본 연구는 은퇴 프 로축구선수 30 명을 1 차 $\mathrm{P}$-표본으로 선정하였으며, $\mathrm{Q}$-분 류 과정에서 신뢰도 문제가 발견된 2 명을 제외한 총 28 명 을 최종 선정하였다. $\mathrm{P}$-표본에 관한 개인적 특성은 〈Table 5〉와 같다.
Table 1. Q-population

\begin{tabular}{|c|c|}
\hline No. & Re-socialization barriers of retired athletes (n) \\
\hline 1 & $\begin{array}{l}\text { Lack of knowledge, Lack of major related job, Social } \\
\text { prejudice, Lack of professional consciousness, Narrow } \\
\text { social network, and Another's eye (6) }\end{array}$ \\
\hline 2 & $\begin{array}{l}\text { Poor financial preparation, Limited human relations, } \\
\text { Limited career choices, Lack of secondary vocational } \\
\text { education, Lack of retirement support programs, and } \\
\text { Lack of career as a athlete (6) }\end{array}$ \\
\hline 3 & $\begin{array}{l}\text { Lack of confidence (psychological confusion) and Lack } \\
\text { of systematic retirement preparation (2) }\end{array}$ \\
\hline 4 & $\begin{array}{l}\text { Lack of confidence due to involuntary retirement, Fear of } \\
\text { new social adjustment, Lack of major related job, and Job } \\
\text { selection irrelevant to major (4) }\end{array}$ \\
\hline 5 & $\begin{array}{l}\text { Lack of retirement preparation, Infringement on right for } \\
\text { learning, Limited personal relationships, and Low career } \\
\text { as a athlete (4) }\end{array}$ \\
\hline 6 & $\begin{array}{l}\text { Lack of self-understanding, Lack of confidence, Lack of } \\
\text { job information, Financial problem, Uncertainty about } \\
\text { the future, and Lack of problem-solving ability (6) }\end{array}$ \\
\hline 7 & $\begin{array}{l}\text { Unfamiliar task, Conflict with co-workers, and Anxiety } \\
\text { about the future (3) }\end{array}$ \\
\hline 8 & $\begin{array}{l}\text { Sense of loss from involuntary retirement, Limited career } \\
\text { choices, Social relationship difficulties, Difficulty in } \\
\text { maintaining career, and Fear of unstable career ( } 5 \text { ) }\end{array}$ \\
\hline 9 & $\begin{array}{l}\text { Limited relationships, Absence of school education, } \\
\text { Feeling of pressure from player reputation, and Stress } \\
\text { from others' eyes and excessive attention (4) }\end{array}$ \\
\hline 10 & $\begin{array}{l}\text { Fear of a new environment, Gender discrimination, Lack } \\
\text { of problem-solving ability, Negative social awareness, } \\
\text { and Lack of social experience (5) }\end{array}$ \\
\hline 11 & $\begin{array}{l}\text { Physical restrictions due to injury, Poor economic } \\
\text { preparation, Not ready for retirement, Lack of confidence } \\
\text { in finding a job, High age in job market, Insufficient } \\
\text { certificates, Limited career choice, High salary and } \\
\text { reputation as a player, Consumption habits during a } \\
\text { player, Lifestyle, Low career as a player, and Treatment } \\
\text { at job (12) }\end{array}$ \\
\hline
\end{tabular}

Source: $1=$ Koo \& Park (2002); $2=$ Myung et al. (2015); $3=\operatorname{Seo}(2012) ; 4=$ Yoon et al. (2013); 5= Jeon \& Park (2009); 6= Hwang \& Choo (2018); $7=$ Choi et al. (2018); 8= Jang \& Kim (2016); 9= Jeon et al. (2004); 10= Lim (2015); 11= Semi-structured interviews 
Table 2. Q-sample

\begin{tabular}{cl}
\hline \hline No. & \multicolumn{1}{c}{ Q-statement } \\
\hline 1 & I have no qualification (certificate, TOEIC, etc.). \\
\hline 2 & I suffer from financial difficulty. \\
\hline 3 & I do not know what kind of job I like. \\
\hline 4 & I have a conflict with my family and friend. \\
\hline 5 & I am unfamiliar with other works except football. \\
\hline 6 & I cannot change my lifestyle as a player. \\
\hline 7 & I have limitations in physical activity due to injury. \\
\hline 8 & There is a social bias towards athletes. \\
\hline 9 & I am old to reemployment. \\
\hline 10 & I was not ready for retirement. \\
\hline 11 & Low career as a footballer is an obstacle. \\
\hline 12 & I lack basic knowledge. \\
\hline 13 & I am anxious about my future life. \\
\hline 14 & My social network is limited. \\
\hline 15 & The treatment of my present or hopeful job is poor. \\
\hline 16 & I have a limited choice of jobs. \\
\hline \hline
\end{tabular}

\section{Q-분류(Q-sort)}

$\mathrm{Q}$-분류는 $\mathrm{P}$-표본(응답자)이 $\mathrm{Q}$-표본을 강제 분류하 는 단계이다. 본 연구에서는 다음과 같은 일련의 과정을 거쳤다. 첫째, 응답자에게 연구 과정에 대해 자세히 설 명한 후 16 개의 $\mathrm{Q}$-표본 카드(〈Table 2$\rangle$ 참고)와 $\mathrm{Q}$-분 류차트(〈Figure 1〉참고)를 제공하였다. 이때 응답자는 16 개의 Q-표본을 충분히 검토한 후 긍정, 부정, 중립 순으로 분류차트의 빈 칸에 분류하였다. 둘째, 분류 과 정에서 한 칸에 $\mathrm{Q}$-표본이 2 개 이상 중복되는 경우에는 연구자의 도움을 받아 응답자 스스로 상대적 우선순위를 강제 분류하였다. 셋째, $\mathrm{Q}-$ 분류가 완성되면 연구자는 응답자에게 재검토 및 수정할 수 있는 기회를 제공하였 다. 마지막으로 $\mathrm{Q}-$ 분류차트의 양극인 -3 와 +3 의 $\mathrm{Q}$-표 본에 대한 분류 이유를 간략히 설명하도록 요구하였다.

\section{Q-요인분석(Q-analysis)}

Q-요인분석은 앞서 수집한 $\mathrm{Q}$-분류차트를 바탕으로 $\mathrm{P}-$ 표본의 주관성(수용인식)을 유형화하는 단계이다. 여

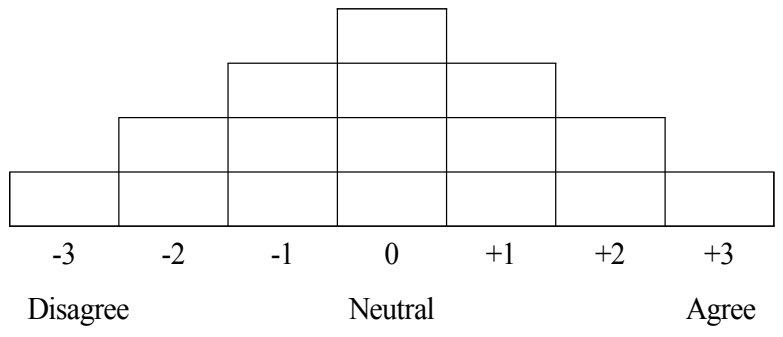

$<$ Figure 1 $>$ Q-sort chart

기서 주관성이란 은퇴 프로축구선수가 지각하는 재사회 화 장벽을 의미하며, 재사회화 장벽에 관한 수용인식이 유사한 개인들(집단)은 하나의 요인으로 추출된다. 이처 럼 변수 간 관계(모형)를 검증하는 양적 연구와 달리, $\mathrm{Q}$ 방법론에서의 요인분석은 개인의 주관성 구조와 그 관계 에 초점을 둔다.

본 연구는 PQmethod(ver.2.35) 소프트웨어 패키 지를 활용하여 다음과 같이 $\mathrm{Q}-$ 요인분석을 실시하였다. 첫째, 프로젝트 생성 후 $\mathrm{Q}$-표본(진술문)에 관한 정보를 코딩하였다. 둘째, $\mathrm{P}$-표본(응답자)에 관한 정보를 코딩 하였다. 셋째, $\mathrm{Q}$ 분류차트에 대한 정보를 코딩하였다. 넷째, 직각회전방법 중 베리맥스(varimax)를 활용한 요인분석을 실시하였으며, 고유치(eigenvalues)는 1.0 이상으로 설정하였다. 마지막으로 요인분석을 통해 추출 된 각 요인(유형)에 관한 해석은 표준점수(Z-score) \pm 1.0 이상인 $\mathrm{Q}$-표본을 대상으로 실시하였다.

\section{결과}

\section{유형 분석}

Q-요인분석을 통해 은퇴 프로축구선수들의 재사회화 장벽에 관한 수용인식은 네 가지 유형으로 관찰되었다. 유형별 고유치는 유형 I 이 7.92로 가장 높게 나타났으 며, 유형 II (3.95), 유형III(3.16), 유형 IV (2.88) 순이다. 각 유형이 설명하는 변량은 유형 I 이 $20 \%$ 를 차지하였으 며, 유형 II (16\%), 유형 III(13\%), 유형 IV (11\%) 순으로 나타났다. 결과적으로 이들 네 개 유형은 전체 변량의 $60 \%$ 를 설명하고 있다. 
유형 간 상관계수는 유형 I 과 유형IV가 .312로 가장 높게 나타난 반면, 유형 I 과 유형Iㅇ은 .031로 가장 낮게 나타났다. 이러한 결과는 네 개 유형 간 상관성이 전반적 으로 독립적임을 의미한다. 유형별 고유치 및 변량은 〈Table 3〉, 유형 간 상관계수는 〈Table 4〉와 같다.

Table 3. Eigenvalues and variation by types

\begin{tabular}{ccccc}
\hline \hline Item & I & II & III & IV \\
\hline Eigenvalues & 7.92 & 3.95 & 3.16 & 2.88 \\
\hline \% expl.Var. & 20 & 16 & 13 & 11 \\
\hline cum\% expl.Var. & 20 & 36 & 49 & 60 \\
\hline \hline
\end{tabular}

Table 4. Correlations between types

\begin{tabular}{ccccc}
\hline \hline Type & I & II & III & IV \\
\hline I & 1 & & & \\
\hline II & .231 & 1 & & \\
\hline III & .031 & .245 & 1 & \\
\hline IV & .312 & .205 & .044 & 1 \\
\hline \hline
\end{tabular}

유형별 $\mathrm{P}$-표본의 전체 분포를 살펴보면, $\mathrm{P}$-표본 28명 중 26 명이 앞서 도출된 네 개 유형을 설명하는 것으로 나 타났다. 구체적으로 10 명이 유형 I 의 전형으로 나타났으 며, 유형 II 8명, 유형III 4명, 유형IV 4명 순이다. 나머지 2 명은 두 개 이상의 유형에서 높은 요인적재치가 확인되 어 결과 분석에 제외하였다. $\mathrm{P}-$ 표본의 유형별 분포, 요인 적재량, 개인적 특성에 관한 내용은 〈Table 5〉와 같다.

\section{유형 해석}

유형 해석은 Q-요인분석에 의해 도출된 네 개 유형을 명명 및 해석하는 단계이다. 본 연구는 표준점수 \pm 1.0 이 상인 Q-표본을 근거로 유형별 특징을 파악한 후 각 유형 에 적합한 주제 (theme)를 부여하였다. 여기서 표준점수 가 높은 $\mathrm{Q}$-표본일수록 강한 긍정을, 낮은 $\mathrm{Q}$-표본일수록 강한 부정을 의미한다. 예컨대, 유형 I 에서 $\mathrm{Q}$-표본 10 번 '은퇴 준비가 부족했다'의 표준점수가 1.0 이상인 경우, 해당 유형의 응답자들이 '은퇴 준비 부족'을 재사회화 장 벽으로 강하게 수용하고 있음을 의미한다. 반대로 -1.0
Table 5. P-sample distribution by type and factor loading

\begin{tabular}{|c|c|c|c|c|c|}
\hline Type & $\begin{array}{l}\text { Age } \\
\text { (y) }\end{array}$ & $\begin{array}{l}\text { Career } \\
\text { (y) }\end{array}$ & $\begin{array}{l}\text { Retirement } \\
\text { reason }\end{array}$ & $\begin{array}{l}\text { Current or } \\
\text { desired job }\end{array}$ & $\begin{array}{l}\text { Factor } \\
\text { loading }\end{array}$ \\
\hline \multirow{10}{*}{$\begin{array}{c}\mathrm{I} \\
(\mathrm{N}=10)\end{array}$} & 31 & 15 & $\begin{array}{c}\text { New } \\
\text { challenge }\end{array}$ & Coach & .716 \\
\hline & $34 *$ & 20 & Military & Public official & .671 \\
\hline & 32 & 13 & $\begin{array}{c}\text { New } \\
\text { challenge }\end{array}$ & Self-employed & .623 \\
\hline & 32 & 17 & $\begin{array}{c}\text { Cancellation } \\
\text { of contract }\end{array}$ & Academy & .665 \\
\hline & 33 & 17 & $\begin{array}{c}\text { New } \\
\text { challenge }\end{array}$ & Coach & .544 \\
\hline & 33 & 15 & Injury & Academy & .714 \\
\hline & 31 & 11 & $\begin{array}{c}\text { Cancellation } \\
\text { of contract }\end{array}$ & Delivery service & .792 \\
\hline & 32 & 16 & $\begin{array}{c}\text { New } \\
\text { challenge }\end{array}$ & Minister & .662 \\
\hline & $31 *$ & 8 & - & - & .606 \\
\hline & 30 & 13 & Injury & P.E. teacher & .552 \\
\hline \multirow{8}{*}{$\underset{(\mathrm{N}=8)}{\mathbb{I}}$} & 34 & 19 & Injury & Coach & .781 \\
\hline & 32 & 16 & Injury & Self-employed & .655 \\
\hline & 31 & 15 & $\begin{array}{c}\text { Cancellation } \\
\text { of contract }\end{array}$ & P.E. teacher & .681 \\
\hline & 33 & 18 & $\begin{array}{c}\text { New } \\
\text { challenge }\end{array}$ & Coach & .627 \\
\hline & 32 & 12 & $\begin{array}{c}\text { New } \\
\text { challenge }\end{array}$ & Actor & .604 \\
\hline & 31 & 15 & $\begin{array}{c}\text { Cancellation } \\
\text { of contract }\end{array}$ & - & .600 \\
\hline & $32 *$ & 17 & Injury & Coach & .599 \\
\hline & $32 *$ & 15 & Injury & Professor & .687 \\
\hline \multirow{4}{*}{$\underset{(\mathrm{N}=4)}{\mathrm{III}}$} & 32 & 15 & Injury & Office worker & .630 \\
\hline & 32 & 12 & Injury & Athletic trainer & .701 \\
\hline & 33 & 10 & $\begin{array}{c}\text { New } \\
\text { challenge }\end{array}$ & $\begin{array}{c}\text { Insurance } \\
\text { planner }\end{array}$ & .807 \\
\hline & 27 & 18 & $\begin{array}{c}\text { Cancellation } \\
\text { of contract }\end{array}$ & Coach & .679 \\
\hline \multirow{4}{*}{$\begin{array}{c}\mathrm{IV} \\
(\mathrm{N}=4)\end{array}$} & 35 & 21 & $\begin{array}{c}\text { New } \\
\text { challenge }\end{array}$ & Agent & .738 \\
\hline & 32 & 13 & $\begin{array}{c}\text { Cancellation } \\
\text { of contract }\end{array}$ & Coach & .586 \\
\hline & $29 *$ & 9 & Injury & Therapist & .721 \\
\hline & 33 & 15 & Injury & - & .687 \\
\hline \multirow{2}{*}{$\begin{array}{c}\text { Invali- } \\
\text { dity } \\
(\mathrm{N}=2)\end{array}$} & 33 & 16 & $\begin{array}{c}\text { Cancellation } \\
\text { of contract }\end{array}$ & Athletic trainer & - \\
\hline & 33 & 15 & Injury & Office worker & - \\
\hline
\end{tabular}

* Interview participants 
이상인 경우에는 재사회화 장벽으로 약하게 수용한 것으 로 해석할 수 있다. 각 유형별 주제 및 해석, 대표 Q-표본 (표준점수 \pm 1.0 이상)에 관한 내용은 다음과 같다.

\section{유형 | : 내적-제약형}

유형 I 은 고유치 9.92 로 총 설명변량의 $20 \%$ 를 설명 하였으며, 10 명의 응답자가 유의미한 상관성을 보이고 있다. 대표 $\mathrm{Q}$-표본, 즉 강한 긍정과 부정을 나타내는 Q표본은 총 4 개로 나타났다. 유형 I 은 '직업 관련 자격요 건(자격증, 공인외국점수 등)이 부족하다 $(\mathrm{Z}=1.213)$ '를 가장 긍정적으로 수용하였으며, '은퇴 준비가 부족했다 $(\mathrm{Z}=1.028)$ '가 그 뒤를 이었다. 반면에 '인적 네트워크가 제한적이다 $(\mathrm{Z}=-1.977)^{\prime}$ 와 '가족, 지인들과 갈등이 있다 $(\mathrm{Z}=-1.861)^{\prime}$ 를 부정적으로 수용하였다. 유형 I 의 대표 $\mathrm{Q}$-표본 및 표준점수에 관한 내용은 〈Table 6>과 같다.

Table 6. Principle Q-sample and Z-score on Type I

\begin{tabular}{clr}
\hline \hline No. & \multicolumn{1}{c}{ Q-sample } & Z-score \\
\hline 1 & I have no qualification (certificate, TOEIC, etc.). & 1.213 \\
\hline 10 & I was not ready for retirement. & 1.028 \\
\hline \hline 4 & I have a conflict with my family and friend. & -1.861 \\
\hline 14 & My social network is limited. & -1.977 \\
\hline \hline
\end{tabular}

긍정적 수용의 주요 핵심어는 '자격요건 미비'와 '은퇴준 비 부족'이며, 부정적 수용은 '인간관계 갈등' 등이다. 이를 종합해볼 때, 유형 I 의 응답자들은 은퇴 후 재사회화 장벽 을 자신의 준비 부족과 자격요건 미흡으로부터 수용하는 유형으로서 '내적-제약형'으로 명명할 수 있다. 다음은 유 형 I 의 응답자들이 대표 Q-표본을 선택한 이유이다.

"자격증이 하나도 없음", "선수 때 지도자 자격증을 준비하지 못함", "토익 점수가 더 이상 안 오른다", "선수 시절 미리 준비하지 못한 것이 후회됨", "인맥은 괜찮다", "다른 사람 이 아니라 내 문제", "내가 노력하지 않으면 안 되기 때문"

\section{유형 II : 외적-제약형}

유형 II는 고유치 3.95 로 총 변량의 $16 \%$ 를 설명하였 으며, 8 명의 응답자가 통계적으로 유의미한 상관성을 보 이고 있다. 대표 Q-표본은 총 4개로 나타났다. 유형 $\Pi$ 의
응답자들은 '선택할 수 있는 직업이 한정적이다 $(\mathrm{Z}=1.870)^{\prime}$ 를 가장 긍정적으로 수용하였으며, '현재 또 는 희망 직업의 처우(소득, 복지, 근무환경)가 열악하다 $(\mathrm{Z}=1.224)^{\prime}$ 가 그 뒤를 이었다. 반면에 '선수시절 생활 (소비) 습관을 바꾸기 힘들다 $(\mathrm{Z}=-1.640)$ '를 가장 부정 적으로 수용하였으며, '부상으로 인해 신체활동에 제한이 있다 $(\mathrm{Z}=-1.060)^{\prime}$ 순이다. 유형 $\Pi$ 의 대표 $\mathrm{Q}$-표본 및 표 준점수에 관한 내용은 〈Table 7 ᄀ과 같다.

Table 7. Principle Q-sample and Z-score on Type II

\begin{tabular}{clr}
\hline \hline No. & \multicolumn{1}{c}{ Q-sample } & Z-score \\
\hline 16 & I have a limited choice of jobs. & 1.870 \\
\hline 15 & The treatment of my present or hopeful job is poor. & 1.224 \\
\hline \hline 7 & I have limitations in physical activity due to injury. & -1.060 \\
\hline 6 & I cannot change my lifestyle as a player. & -1.640 \\
\hline \hline
\end{tabular}

긍정적 수용의 핵심어는 '한정적인 직업' ,열악한 처우' 이며, 부정적 수용은 '생활 습관', '신체 건강' 등이다. 이 를 종합해볼 때, 유형 II는 은퇴 후 재사회화 장벽을 개인 내부보다는 외부 조건으로부터 수용하는 유형으로서 '외 적-제약형'으로 분류할 수 있다. 다음은 유형 $\Pi$ 의 응답자 들이 대표 $\mathrm{Q}$-표본을 선택한 이유이다.

"축구부 코치는 생계가 쉽지 않다", "선출들을 위한 일자리 가 부족하다", "전공을 살리기에는 직업이 매우 부족함", "지도자 대우는 너무 초라하다", "몸은 건강하다", "좋은 일 만 할 수 있다면 도전할 자신 있다"

\section{유형III: 내적-갈등형}

유형Iㅣ은 고유치 3.16 로 총 변량의 $13 \%$ 를 설명하였 으며, 4 명의 응답자가 통계적으로 유의미한 상관성을 보 이고 있다. 대표 $\mathrm{Q}$ 표본은 총 5 개로 나타났다. 유형Iㅣㅇㅢ 응답자들은 '어떤 직업을 좋아하는지 모르겠다 $(\mathrm{Z}=1.810)^{\prime}$ 를 가장 긍정적으로 수용하였으며, '축구 외 다른 업무가 생소하다 $(\mathrm{Z}=1.625)$ ', '선수시절 생활(소비) 습관을 바꾸기 힘들다 $(\mathrm{Z}=1.029)$ ' 순이다. 반면에 '운동 선수에 대한 사회 편견이 있다 $(\mathrm{Z}=-1.352)$ '를 가장 부정 적으로 수용하였으며, '재취업하기에 나이가 많다 $(\mathrm{Z}=-1.165)^{\prime}$ 순이다. 유형 $I I$ 의 대표 $\mathrm{Q}$-표본 및 표준점 
수에 관한 내용은 〈Table 8>과 같다.

Table 8. Principle Q-sample and Z-score on Type III

\begin{tabular}{clr}
\hline \hline No. & \multicolumn{1}{c}{ Q-sample } & Z-score \\
\hline 3 & I do not know what kind of job I like. & 1.810 \\
\hline 5 & I am unfamiliar with other works except football. & 1.625 \\
\hline 6 & I cannot change my lifestyle as a player. & 1.029 \\
\hline \hline 9 & I am old to reemployment. & -1.165 \\
\hline 8 & There is a social bias towards athletes. & -1.352 \\
\hline \hline
\end{tabular}

긍정적 수용의 핵심어는 '적성 미발견', '낮선 업무’, '생 활 습관'이며, 부정적 수용은 '사회 편견', '나이 제한' 등이 다. 이를 종합해볼 때, 유형Iㅣ은 은퇴 후 재사회화 장벽을 외부 조건보다는 개인의 정서적 혼란으로부터 수용하는 유형으로서 '내적-갈등형'으로 명명할 수 있다. 다음은 유 형Iㅣㅇㅢ 응답자들이 대표 Q-표본을 선택한 이유이다.

"직장을 몇 번 바꿨다", "지금 하고 있는 일이 내가 잘하는 건지, 좋아하는 건지 모르겠다", "선수 때 쓰던 생활비를 줄 이기가 힘들다", "스스로 내 진로에 확신이 없다"

\section{유형IV: 외적-갈등형}

유형IV는 고유치 2.88 로 총 변량의 $11 \%$ 를 설명하였 으며, 4 명의 응답자가 통계적으로 유의미한 상관성을 보 이고 있다. 대표 Q-표본은 총 4개로 나타났다. 유형 $\mathrm{IV}$ 의 응답자들은 '재취업하기에 나이가 많다 $(\mathrm{Z}=2.110)$ '를 가 장 긍정적으로 수용하였으며, '운동선수에 대한 사회 편 견이 있다 $(\mathrm{Z}=1.002)$ ' 순이다. 반면에 '부상으로 인해 신 체활동에 제한이 있다 $(\mathrm{Z}=-1.394)$ '와 '선수시절 생활(소 비) 습관을 바꾸기 힘들다 $(\mathrm{Z}=-1.303)$ '를 부정적으로 수 용하였다. 유형 IV의 대표 Q-표본 및 표준점수에 관한 내 용은 〈Table 9 )과 같다.

Table 9. Principle Q-sample and Z-score on Type IV

\begin{tabular}{clr}
\hline \hline No. & \multicolumn{1}{c}{ Q-sample } & Z-score \\
\hline 9 & I am old to reemployment. & 2.110 \\
\hline 8 & There is a social bias towards athletes. & 1.002 \\
\hline \hline 6 & I cannot change my lifestyle as a player. & -1.303 \\
\hline 7 & I have limitations in physical activity due to injury. & -1.394 \\
\hline \hline
\end{tabular}

긍정적 수용의 핵심어는 '나이 제한', '사회 편견'이며, 부정적 수용은 '신체 건강', '생활 습관' 등이다. 이를 종합 해볼 때, 유형 IV는 유형 II 와 같이 개인 외부로부터 재사 회화 장벽을 수용하고 있으나 외부 조건(객관)보다는 사 회적 관념(주관)에 가까운 유형으로서 '외적-갈등형'으로 명명할 수 있다. 다음은 유형 $\mathrm{V}$ 의 응답자들이 대표 $\mathrm{Q}$-표 본을 선택한 이유이다.

\section{"새로운 도전을 하기에는 나이가 걸림돌", "어린 친구들보 다 경쟁력이 떨어진다", "운동했다고 하면 무식하게 볼까 봐", "운동선수 출신을 숨기고 지낸 적이 많음"}

\section{논의}

앞서 본 연구는 은퇴 프로축구선수들의 재사회화 장벽 을 ‘유형 I : 내적-제약형', ‘유형 II : 외적-제약형', ‘유형 III : 내적-갈등형', ‘유형IV : 외적-갈등형'으로 분류 및 명 명하였다. 그리고 이들 유형은 재사회화 장벽을 수용하는 두 가지 기준, 즉 (1) 어디로부터 수용하는지 (개인 내부 와 외부); (2) 무엇에 의존하는지(객관적 조건과 주관적 관념)에 따라 재분류할 수 있다. 따라서 본 장에서는 두 기준을 해석 틀로 차용하여 각 유형에 관한 학술적 또는 실용적 논의를 제공하고자 한다. 위 두 기준에 따른 유형 분류는〈Figure 2 〉와 같다.

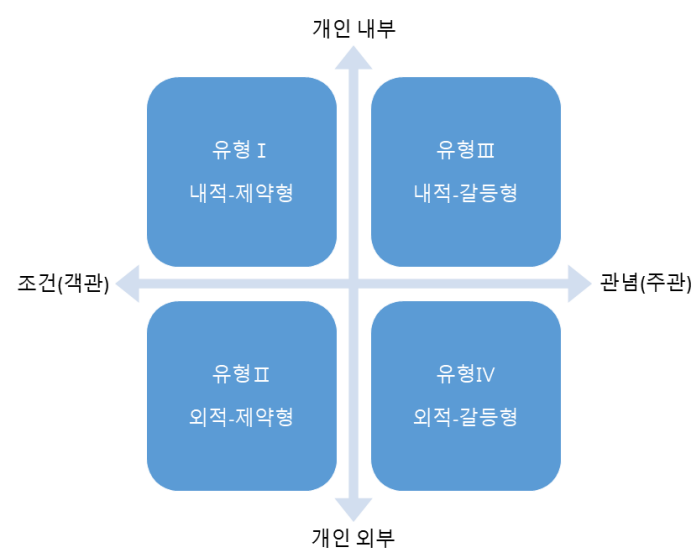

Figure 2. Re-socialization barriers of retired footballers 
첫째, '내적-제약형(유형 I )'이다. 유형 I 은 자신의 은 퇴 준비 부족과 자격요건 미흡을 은퇴 후 재사회화 장벽 으로 높게 인식하였다. 이는 재사회화 장벽의 원인을 개 인 내부로부터 수용하는 동시에 개인 역량과 같은 객관적 조건에 의존하는 것으로 해석할 수 있다. 여기서 언급한 객관적 조건이란 구직에 필요한(또는 명시된) 학력 및 경 력, 자격증, 공인외국어점수 등이며, 유형 I 은 이들 조건 에 대해 스스로 대비(노력)하지 못한 점을 재사회화 장벽 으로 수용하였다.

유형 I 의 사례는 현행 은퇴 선수 지원사업에 관한 개 선 방안을 제공한다. 대한체육회에서 주관하는 '맞춤형직 업훈련', '취업지원서비스, '멘토링' 등은 20세 이상 은퇴 선수를 지원 대상으로 제한하고 있으며 (KSOC website, 2019, Nov 27), 현직 성인 선수를 대상으로 한 은퇴 지 원사업은 전무한 실정이다. 또한, 체육인재아카데미(구 체육인재육성재단)에서 주관하는 '직무역량 강화교육', '차세대 체육인재 경력개발', '선진형 교육문화 확산' 역시 은퇴 선수, 현직 지도자 및 행정가를 주요 대상으로 규정 하고 있다(Korea Sports Promotion Foundation website, 2019, Nov 27). 그러나 현행 지원사업과 달리 유형 I 의 사례는 현직 선수 시절부터 체계적인 은퇴 준비 의 필요성을 시사하고 있다. 이는 은퇴 준비 수준이 재사 회화에 직접적인 영향을 미치는 동시에 은퇴 기대에도 매 개한다는 $\operatorname{Seo}(2012)$ 의 연구에서도 검증된 바 있다. 근거 이론을 활용한 Jeon \& Park(2009) 역시 은퇴 준비 유무 에 따라 태권도 선수들의 재사회화 적응 유형이 다르게 나타난다고 보고하였다. 구체적으로 은퇴 준비 행동을 보 였던 집단은 발전지향형으로, 그렇지 않은 집단은 안주 형, 전환형, 혼란형으로 분류되었다. 이러한 사실은 현행 은퇴 선수 지원사업의 대상을 은퇴 선수에서 현직 선수로 확대 적용할 근거로서 학술적 및 실용적 의의가 있다.

둘째, '외적-제약형(유형 II)'이다. 유형 II는 한정된 직 업선택의 폭, 열악한 처우 등 외부 조건을 재사회화 장벽 으로 높게 인식하였다. 이는 객관적 조건으로부터 재사회 화 장벽을 설명한 유형 I 과 유사하지만 그 조건이 개인 내부가 아닌 외부에 있다는 점에서 차이가 있다. 다시 말 해, 유형 $\Pi$ 는 자신의 역량 및 노력 부족보다는 개인 외부 에 존재하는 '구직환경'을 재사회화 장벽으로 높게 수용하 였다.
유형Iㅇㅇㅢ 전형은 다수 선행연구에서 보고된 사례 (Jang \& Kim, 2016; Koo \& Park, 2002; Myung et al., 2015; Yoon et al., 2013)로서 국내 은퇴 선수들이 겪는 현실적인 어려움이다. 여기서 '한정된 직업선택의 폭'과 '열악한 처우’는 은퇴 선수들이 자신의 종목(전공) 과 연관된 직업이 제한적이거나 다른 분야로의 진출에 어 려움을 겪고 있음을 의미한다. Myung et al.(2015)는 현직 프로축구선수들의 은퇴 인식 및 준비 행동을 탐색한 결과, 참여자들이 은퇴 후 새로운 분야로의 진출을 희망 함에도 불구하고 해당 종목의 지도자를 선택할 수밖에 없 는 구조적 한계를 언급하였다. 또한, 참여자들의 진술 내 용에서 은퇴 후 희망 직업으로 '지도자'를 빈번히 발견할 수 있었는데 그 이면에는 '어쩔 수 없이 선택하는 것', '내 가 할 수 있는 것은 지도자뿐'이라는 현실이 존재한다 (Myung et al., 2015). 이러한 사실은 국내 은퇴 선수 중 $54.8 \%$ 가 체육 관련 직종을 선택하고, $61.9 \%$ 가 체육 관 련 직종을 희망한다는 $\mathrm{KSOC}(2012)$ 의 조사 결과에 다른 시각과 해석을 요구한다. 양적 조사를 통해 밝혀진 단편 적 사실에 대한 물음, 즉 '왜 다수의 은퇴 선수들이 지도 자를 희망하는지’ 그 배경에 대한 사회구조적 원인을 심 층조사하고 그에 따른 정책적 반영이 고려되어야 한다.

셋째, '내적-갈등형(유형III)'이다. 유형 III은 재사회화 장벽으로 적성 미발견, 적응, 생활습관 등 불확실성을 높 게 인식하였다. 이는 객관적 조건을 재사회화 장벽으로 인식한 유형 I 및 유형 II 와는 달리, 주관적 관념에 의존 한 것으로 해석할 수 있다. 즉 유형Iㅣ은 자신의 흥미와 적 성에 대한 불확실, 선수시절 형성된 정체성 및 환경 변화 에 대한 두려움 등 개인 내부의 정서적 혼란을 재사회화 장벽으로 수용하였다.

유형Iㅣ은 은퇴 선수들이 사회 적응 과정에서 겪는 정 서적 불안의 전형이다. 실제로 Hwang \& Choo(2018)는 은퇴 선수 지원 프로그램을 개발하기 위한 첫 번째 전제 조건으로 자아 찾기, 자존감 찾기, 목표 설정 등 '자기이 해 프로그램'을 주장하였다. 다른 연구에서도 은퇴 선수 들이 심리적 불안과 상실감을 경험한 것으로 보고된 바 있다(Choi et al., 2018; Jang \& Kim, 2016). 그리고 다수의 선행연구는 정서적 불안으로 대표되는 유형피의 전형을 '은퇴 요인'으로부터 설명하였다. 다시 말해, 은퇴 결정에 어떠한 요인이 영향을 미쳤는지에 따라 정서적 불 
안을 경험할 수도, 그렇지 않을 수도 있다는 것이다. 그중 본 연구는 부상, 일방적 계약해지, 재계약실패 등 ‘비자발 적 은퇴'에 주목하고자 한다. 비자발적 은퇴를 경험한 선 수들은 사회적 죽음(social death)에 대한 두려움 (Blinde \& Stratta, 1992; Fortunato \& Marchant, 1999; Zaichkowsky et al., 2000), 배신감과 사회적 배 제(McKenna \& Thomas, 2007), 정체성 상실(Butt \& Molnar, 2009; Lynch, 2006) 등 높은 수준의 부정적 감 정을 경험하기 때문이다. 반면에 Erpič et al.(2004)과 Newell(2005)은 선수로서 경력이 높은 은퇴 선수들은 은퇴 후 진로 전환에 있어 자기 능력에 대해 긍정적인 신 념을 보인다고 하였다. 이러한 사실은 스포츠선수들의 은 퇴 시기와 원인에 따라 차별화된 은퇴 지원 프로그램이 필요하며 특히, 비자발적 은퇴 선수에게는 재취업에 필요 한 자격요건뿐만 아니라 정서적 지지가 고려되어야 함을 시사한다.

넷째, '외적-갈등형(유형 IV)'이다. 유형IV는 취업 연령 과 운동선수에 대한 편견 등 사회적 고정관념을 재사회화 장벽으로 높게 인식하였다. 이는 주관적 관념에 의존하는 유형피과 유사하지만 그 관념을 개인 내부보다는 외부 (사회)로부터 수용한다는 점에서 차이가 있다. 다시 말 해, 유형 $\mathrm{V}$ 는 정서적 불안이나 혼란보다는 자신(예컨대, 운동선수, 나이)을 둘러싼 사회적 편견과 고정관념을 재 사회화 장벽으로 지각(경험)한 것으로 이해할 수 있다.

유형IV는 타인의 시선으로부터 재사회화 장벽을 수용 하고 있으며 이 유형은 주로 국가대표 경력이 있는, 즉 높 은 커리어를 지닌 선수들 사이에서 공통적으로 발견된다 (Choi, 2014; Jeon et al., 2004; Lim, 2015). 성별은 다르지만 여성 테니스 국가대표 선수의 재사회화 과정을 탐색한 $\operatorname{Lim}(2015)$ 는 국가대표 타이틀은 선수로서 성공 적 삶을 대변하는 반면, 은퇴 후 진로 전환과정에서는 사 회 경험 부족이라는 부정적 인식을 가져온다고 하였다. 마찬가지로 국가대표 선수들을 대상으로 한 Choi(2014) 의 연구에서도 참여자들에게 국가대표는 자랑스러운 명 예임과 동시에 자신을 속박하는 사회적 낙인으로 기능한 다고 하였다. 다시 말해, 선수로서 높은 커리어는 선수의 삶과 은퇴 후 삶에서 이중성을 나타내는데, 본 연구의 P표본 역시 프로축구선수 경험이 있는 자들로서 해당 종목 에서 높은 수준의 경력을 지니고 있다. 이처럼 유형 $\mathrm{IV}$ 의
전형은 중도탈락을 경험한 학생선수와 낮은 경력을 지닌 선수보다는 상대적으로 높은 경력을 지닌 은퇴 선수들 사 이에서 더욱 두드러진다.

이에 대해 $\operatorname{Lim}(2015)$ 와 Jeon et al. (2004)는 전문 운 동선수의 학습권 부재와 기초학습능력 결여를 그 원인으 로 지적하였다. 본 연구 역시 이들 주장에 대해 이견은 없 지만 은퇴 선수 지원 측면에서 보다 실용적인 논의가 필 요하다. 유형 $\mathrm{IV}$ 의 사례는 은퇴 후 재취업 과정에서 자신 을 둘러싼 사회적 편견을 극복하고 궁극적으로 안정적인 재사회화를 경험하는 것이 중요하다. 이러한 관점에서 대 한체육회에서 주관하는 현행 '은퇴 선수 잡매칭 (welfare.sports.or.kr)' 지원사업은 좋은 사례가 될 수 있다. 은퇴 선수 잡매칭은 은퇴 선수와 기업이 각각 구인, 구직활동을 하는데 필요한 매체와 정보를 지원하는 것으 로 주로 스포츠산업이 그 대상이다. 은퇴 선수를 직접 명 시하지 않았지만 국민체육진흥공단의 '스포츠산업 구인 구직 매칭서비스(spobiz.kspo.or.kr)'도 유사한 성격을 지니고 있다. 이들 사업은 스포츠 관련 전공자(은퇴 선수 포함)를 채용하는 기업들과 은퇴 선수가 상호작용한다는 특징이 있다. 이는 재사회화 과정에서 사회적 편견과 구 직활동의 심리적 제약을 경험한 유형 $\mathrm{IV}$ 에게 실효성 높은 지원책이 될 수 있다. 일방적 구직활동이 아닌 자신을 필 요로 하는 기업들과 연결함으로써 유형 IV가 수용한 재사 회화 장벽을 일부 해소할 수 있기 때문이다. 따라서 잡매 칭 서비스의 효율적 운영을 위해서 은퇴 선수와 스포츠 관련 전공자로 양분된 해당 사업들의 연계(또는 일원화) 작업과 양질의 일자리 및 다양한 기업의 참여를 촉진할 필요가 있다. 무엇보다 전·현직 스포츠선수를 대상으로 한 적극적인 홍보 및 교육이 선행되어야 한다. 그도 그럴 것이 최근 실시한 은퇴 선수 실태조사(KSOC, 2018)에 따르면, 응답자 중 $72.9 \%$ 가 은퇴 선수 지원사업을 전혀 인지하지 못했으며 특히, 20 대의 경우 $62.2 \%$ 로 가장 높 게 나타났다.

\section{결론 및 제언}

고도화된 기술 혁명과 과학의 진보에 따른 사회 변화 속에서 현대인의 건강을 과거 $\mathrm{WHO}$ 가 정의한 신체적, 정 
신적, 사회적 영역으로 설명하는데 한계에 직면했다. 그 대안적 개념으로 직업적, 재정적, 지적, 환경적 영역이 추 가된 웰니스(wellness)가 현대인의 건강, 즉 인간다운 삶 을 규정하는 시대이다. 더욱이 고령사회에 들어선 한국 사회는 경제활동인구의 감소(역으로 퇴직 인구의 증가) 와 그에 따른 직업·재정적 건강이 새로운 사회 논제로 주 목받고 있다. 은퇴와 은퇴 후 삶에 대한 지적 관심이 그 대표적인 현상이다. 이런 맥락에서 일반 노동시장과 다른 양상을 보이는 스포츠선수의 은퇴는 보다 독립적이고 심 층적인 논의가 요구되는 실정이다. 특히, 국내 체육계의 구조적 특성과 각 종목의 사회문화적 특수성을 고려하여 은퇴 선수와 관련된 다각적 논의가 축적되어야 한다.

이러한 문제의식으로부터 본 연구는 은퇴 프로축구선 수들의 재사회화 장벽에 관한 주관성(수용인식)을 유형 화하는데 주목하였다. 구체적으로 $\mathrm{Q}$ 방법론을 분석 틀로 차용하여 은퇴 선수들이 지각(또는 경험)한 사회적응 및 재취업 과정에서의 제약 요인을 규명하였다. 그 결과, 은 퇴 프로축구선수들의 재사회화 장벽은 '유형 I : 내적-제 약형’, ‘유형 II : 외적-제약형’, ‘유형 III : 내적-갈등형’, ‘유 형 $\mathrm{IV}$ : 외적-갈등형'으로 관찰되었다. 이들 유형은 재사회 화 장벽을 어디로부터 수용하는지 (개인 내부와 외부), 무 엇에 의존하는지 (객관적 조건과 주관적 관념)에 따라 다 양한 학술적 및 실용적 논의를 제공하였다. 각 유형의 특 징과 의의를 요약하면 다음과 같다.

첫째, '유형 I : 내적-제약형'은 은퇴 준비 부족과 자격 요건 미흡을 재사회화 장벽으로 높게 인식하였는데, 이는 재사회화 장벽의 원인을 개인 내부로부터 수용하는 동시 에 개인 역량과 노력 부족에 의존한 것이다. 유형 I 의 사 례는 현직 선수 시절부터 은퇴 준비의 필요성과 중요성을 시사한다. 더 나아가 은퇴 선수로 한정되어 있는 현행 은 퇴 선수 지원사업의 대상 범위를 현직 선수로 확대 적용 할 근거로서 학술적 및 실용적 의의가 있다.

둘째, '유형 II : 외적-제약형'은 한정된 직업선택의 폭, 열악한 처우 등 외부 조건을 재사회화 장벽으로 높게 인 식하였다. 이는 객관적 조건으로부터 재사회화 장벽을 설 명한 유형 I 과 유사하지만 개인 역량 및 노력 부족보다는 개인 외부에 존재하는 구직환경을 높게 수용한 것이다. 유형 II 의 전형은 국내 은퇴 선수들이 겪는 현실적인 어려 움으로 자신의 종목(전공)과 연관된 직업이 한정적이거
나 다른 분야로의 진출에 제한이 있음을 의미한다. 이러 한 사실은 국내 은퇴 선수 중 다수가 지도자를 희망하거 나 선택하고 있다는 사회조사 결과에 대한 다른 시각과 해석을 요구한다. 이에 본 연구는 은퇴 선수들의 2 차 직 업선택에 관한 사회구조적 요인과 그에 따른 정책 방안을 후속연구의 과제로 제안한다.

셋째, '유형 III: 내적-갈등형'은 객관적 조건을 재사회 화 장벽으로 인식한 유형 I , 유형 II 와 달리, 자신의 흥미 와 적성에 대한 불확실, 선수시절 형성된 정체성 및 환경 변화에 대한 두려움 등 주관적 관념에 의존하였다. 유형 III은 은퇴 선수들이 사회 적응 과정에서 겪는 정서적 불 안의 전형으로, 이는 ‘비자발적 은퇴’라는 은퇴 요인으로 설명할 수 있다. 이러한 사실은 비자발적 은퇴를 경험한 선수에게는 객관적 조건뿐만 아니라 정서적 지지가 고려 되는 등 은퇴 요인에 따른 맞춤형 지원 프로그램의 필요 성을 시사한다.

넷째, '유형 IV: 외적-갈등형'은 자신의 연령과 운동선 수에 대한 편견 등 사회적 고정관념을 재사회화 장벽으로 높게 인식하였다. 이는 주관적 관념을 개인 내부보다는 외부(사회)로부터 수용한다는 점에서 유형Iㅣㄱㅘ 차이가 있다. 유형 IV는 높은 커리어를 지닌 선수들 사이에서 공 통적으로 발견되는 전형으로서 타인의 시선을 재사회화 장벽으로 수용하였다. 이에 본 연구는 은퇴 선수와 기업 이 각각 구인, 구직활동에 필요한 매체와 정보를 지원하 는 현행 ‘은퇴 선수 잡매칭' 및 '스포츠산업 구인구직 매칭 서비스'를 지원책으로 논의하였다. 따라서 해당 사업들의 일원화 체계 구축과 다양한 산업 분야의 참여 촉진 그리 고 전·현직 스포츠선수를 대상으로 한 적극적인 홍보 및 교육을 제안한다.

끝으로 본 연구는 $\mathrm{Q}$ 방법론을 통해 은퇴 프로축구선수 들의 재사회화 장벽을 유형화함으로써 전통 방법론의 한 계를 보완하였다. 이는 가설 검증에 주목한 선행연구들과 달리, 개인의 주관성 구조로부터 가설 추론(발견)에 초점 화된 연구로 평가할 수 있다. 이처럼 본 연구에서 발견한 각 유형(요인)들은 은퇴 선수와 관련된 후속 연구뿐만 아 니라 지원사업과 같은 정책 결정 과정에도 유용한 정보를 제공하고 있다. 더 나아가 인간 심리와 행 동에 대한 이해 를 전제하는 체육학 연구에서 $\mathrm{Q}$ 방법론이 지닌 발견적 추 론의 특성과 학술적 유용성을 제고할 수 있었다. 
이러한 기여에도 불구하고 본 연구의 $\mathrm{P}$-표본이 상대적 으로 높은 경력을 갖춘 남성 선수로 구성된 점은 중도탈 락 학생선수와 낮은 경력의 은퇴 선수 그리고 여성 선수 의 사회문화적 특성을 반영하지 못한 한계이기도 하다. 따라서 후속연구에서는 다양한 은퇴 시기와 요인을 고려 한 접근 및 비교 분석이 보완되어야 할 것이다. 무엇보다 도 사회구성원으로서 은퇴 선수의 고립 문제와 제도적 보 호 장치에 보다 많은 지적 관심을 기대해본다.

\section{참고문헌}

Blinde, E. M., \& Stratta, T. M. (1992). The 'sport career death' of college athletes: Involuntary and unanticipated sports exits. Journal of Sport Behavior, 15, 3-20.

Butt, J., \& Molnar, G. (2009). Involuntary career termination in sport: A case study of the process of structurally induced failure. Sport in Society, 12, 240-257.

Choi, G. J., Lim, S. W., \& Jeon, W. J. (2018). The exploring the process of resocialization of soccer retirement athletes into worker's soccer teams. The Korean Journal of Physical Education, 57(4), 103-116.

Choi, H. Y., \& Chung, Y. C. (2012). The narratives of retired female handball players. The Korean Journal of Physical Education, 51(6), 83-93.

Choi, J. S. (2014). Exploring the retirement experience and career transition of former national athletes. Journal of Sport and Leisure Studies, 57(1), 323-337.

Choi, Y. M., Chung, S. P., Jun, S. D., \& Kim, K. (2011). A Q-methodological factor analysis for activating badminton clubs in sports for all-focusing on members' opinions. The Korean Society of Sports Science, 20(2), 57-69.

Chung, I. H. (2007). Desocialization of aesthetic rhythmic sports athletes. Journal of Korean Society of Sport, 20(1), 67-84.

Chung, J. H. (2010). In research of women's national basketball team players' perception of retirement. Korean Journal of Sport Science, 21(1), 1055-1066.

Erpič, S. C., Wylleman, P., \& Zupančič, M. (2004). The effect of athletic and non-athletic factors on the sports career termin ation process. Psychology of sport and exercise, 5(1), 45-59.

Fortunato, V., \& Marchant, D. (1999). Forced retirement from elite football in Australia. Journal of Personal and Interpersonal
Loss, 4, 269-280.

Hwang, M. G., \& Choo, J. H. (2018). Explore the preconditions for developing a career development program for retired elite soccer players. The Korean Journal of Sport, 16(1), 509-516.

Im. H. J. (2019). Perception types of elders of participation in sports for all program on sport. Korean Journal of Physical Education, 58(4), 287-298.

Jang, M. R. (2016). The relationship between retirement expectation, sense of psychological crisis and re-socialization among the national representative athletes. Journal of Sport and Leisure Studies, 66, 229-241.

Jang, S. H., \& Kim, I. H. (2016). Retirement circumstances and social adaptation experience in the re-socialization process of badminton players. The Korean Journal of Physical Education, 55(5), 29-41.

Jeon, I. G., Won, Y. S., \& Lee, J. H. (2004). A study for the desocialization and resocialization of olympic medalists. The Korean Journal of Physical Education, 43(1), 141-151.

Jeon, J. W., \& Park, S. U. (2009). A process for desocialization and re-socialization of taekwondo player's. The Korean Journal of Physical Education, 48(5), 53-63,

Jung, J. H., Kim, H. M., \& Lee, H. S. (2019). Attitude types of students without disabilities on inclusive swimming. Journal of adapted physical activity and exercise, 27(1), 47-59.

Kim, C. H., \& Hong, J. S. (2015). The study of perception on retirement for professional soccer players. Korean Journal of Sport Science, 26(2), 320-328.

Kim, C. H., \& Son, J. W. (2017). The factor analysis of constraints for spectating professional football game of soccer club members: Q methodological approach. Journal of Sport and Leisure Studies, 69, 81-94.

Kim, H. K. (1992). Understanding and applying of Q methodol ogy. Seoul: Sogang University Journalism \& Culture Institute.

Kim, H. K. (2008). Q methodology: Philosophy of science, the oy, analysis and application. Seoul: Communicationbooks.

Kim, H. M., Kim, S. H., Park, J. W., \& Lee, H. S. (2015). Investigation of sports for all requirement types of people with intellectual disability: Focused on Q methodology. Korean Journal of Physical Education, 54(1), 597-609.

Kim, J. H. (2012). A Q-methodical factor analysis to activate old persons' health and welfare facilities: Centering on the workers engaging in the facilities. The Korean Society of Sports Science, 21(3), 147-160. 
Kim, O. H. (2019). A study of physical education class cognition of middle school students. Korean Journal of Physical Education, 58(4), 55-72.

Kim, S. R., \& Lee, J. R. (2016). An exploration about social networking process of retired athletes. Korean Journal of Physical Education, 55(6), 67-83.

Kim, Y. R. (2014). The retired female athletes' actual conditions of employment and support plans for their employment. Journal of Korean Physical Education Association for Girls and Women, 28(2), 49-69.

Koo, C. M., \& Park, K. H. (2002). A study on retirement and future career of Korean gold medalists. Journal of Korean Society of Sport, 15(1), 71-84.

Korea Sports Promotion Foundation website. (2019, Nov 27). Retrieved from https://nest.kspo.or.kr/site/main/index001

Korean Sport \& Olympic Committee. (2012). An investigation on living status of retired athletes. Seoul: KSOC.

Korean Sport \& Olympic Committee. (2018). 2018 Survey on retired athletes and job findings. Seoul: KSOC.

Korean Sport \& Olympic Committee website. (2019, Nov 27). Retrieved from https://welfare.sports.or.kr/job/index.do

Korean Society for the Science Study of Subjectivity. (2002). Subjectivity study. Seoul: Communicationbooks.

Korean Society for the Science Study of Subjectivity. (2014). Application and Case of Q methodology. Seoul: Prunsasang.

Korean Statistical Information Service. (2019). Employment trend 2019. Daejeon: KOSIS.

Lee, D. Y., \& Park, C. B. (2012). A study on the desocialization form sport of track and field athletes. The Korean Society of Sports Science, 21(5), 169-183.

Lee, G. B., \& Park, B. K. (2009). Retirement and social adaptation process in gymnast. Journal of Sport and Leisure Studies, 36, 795-805.

Lee, J. W., Jeon, S. M., \& Kim, K. (2011). A Q-methodological factor analysis for attracting the audience to professional volleyball games: Focusing on the opinions of players and the staff. The Korean Society of Sports Science, 20(4), 35-50.

Lee, Y. S. (2008). A study on retirement preparation and career support for national athlete in Korea. Korean Journal of Sport Science, 19(4), 136-146

Lim, S. M. (2015). The difficulties of former female national tennis team members in re-socialization process. The Korean Journal of Physical Education, 54(3), 75-87.

Lynch, D. (2006). Adjustment to retirement of horse racing jockey. Unpublished master's thesis. Victoria University.

McKenna, J., \& Thomas, H. (2007). Enduring injustice: A case study of retirement from professional rugby union. Sport, Education, and Society, 12, 19-35.

McKeown, B., \& Thomas, D. B. (2013). Q methodology (Vol. 66). CA: Sage Publications.

Myung, W. S., Won, Y. S., \& Koo, S. K. (2015). A study on K-League players' perception and preparation process on retirement. Korean Journal of Sport Science, 26(2), 254-266.

Newell, C. P. Q. (2005). Identification of intrinsic, interpersonal, and contextual factors influencing disengagement from high performance sport. Unpublished doctoral dissertation. University of British Columbia.

Park, D. J., \& Won, Y. S. (2014). Career transition process of former Korean national ice hockey players. Journal of Korean Society of Sport, 27(2), 27-53.

Park, H. S. (2018). New sport activation plan through the awareness of the physical education instructors: An approach by $\mathrm{Q}$ methodology. The Journal of Learner- Centered Curriculum and Instruction, 18(10), 791-820.

Seo, Y. H. (2012). The structural relationship among athlete's retirement expectation, psychological sense of crisis, level of retirement preparation and re-socialization. The Korean Society of Sports Science, 21(4), 393-406.

Stephenson, W. (1953). The study of behavior: Q-technique and its methodology. IL: University of Chicago Press.

Watts, S., \& Stenner, P. (2005). Doing Q methodology: Theory, method and interpretation. Qualitative Research in Psychology, 2(1), 67-91.

Yoon, T. H., Kang, D. M., Yang, S. H., Yoo, Y. J., Kim, T. H., \& Kang, Y. W. (2013). De-socialization and re-socialization of the national aerobic gymnastic players. The Korean Society of Sports Science, 22(1), 301-317.

Zaichkowsky, L., King, E., \& McCarthy, J. (2000). The end of an era: The case of forced transition involving Boston University football. Career transitions in sport: International perspectives, 195-205. 


\title{
은퇴 프로축구선수들의 재사회화 장벽에 관한 수용인식 유형화
}

\author{
명왕성 ${ }^{1}$, 박광호 $^{1}$, 정경환 ${ }^{2}$ \\ ${ }^{1}$ 연세대학교, 강사 \\ 2연세대학교, 박사과정
}

[목적〕 본 연구는 은퇴 프로축구선수들의 재사회화 장벽에 관한 수용인식(주관성)을 유형화하는데 그 목적 이 있다. 〔방법) $\mathrm{Q}$ 방법론을 차용하여 은퇴 선수들이 지각(또는 경험)한 사회적응 및 재취업 과정에서의 제약 요인을 규명하였다. 〔결과〕 은퇴 프로축구선수들의 재사회화 장벽은 ‘유형 I : 내적-제약형’, ‘유형 II : 외적-제 약형', ‘유형 III : 내적-갈등형', ‘유형 IV: 외적-갈등형’으로 나타났다. 이들 유형은 재사회화 장벽을 어디로부터 수용하는지(개인 내부와 외부), 무엇에 의존하는지(객관적 조건과 주관적 관념)에 따라 다양한 학술적 및 실 용적 논의를 제공하였다. 〔결론) 본 연구는 개인의 주관성 구조, 즉 가설 추론(발견)에 초점화된 연구로서 가 설 검증에 주목한 전통 방법론을 보완하였다. 따라서 본 연구에서 발견한 각 유형들은 은퇴 선수와 관련된 후 속 연구뿐만 아니라 지원사업과 같은 정책 결정 과정에도 유용한 정보를 제공한다.

주요어: 축구선수, 은퇴, 탈사회화, 재사회화, 장벽, $\mathrm{Q}$ 방법론, 주관성 